\title{
Supporting the socio-emotional aspects of the primary-secondary transition for pupils with social, emotional and behavioural needs: Affordances and Constraints
}

\author{
Keywords \\ Primary-Secondary Transition \\ Social and Emotional Behavioural Needs \\ Inclusive Practice \\ Sense of Belonging \\ Leadership
}

\section{Abstract}

The primary-secondary transition presents both opportunities and challenges for children. For some, it may represent a 'critical period' which impacts on their future mental health and wellbeing. This paper focuses on identifying the affordances and constraints of a group-work approach to support children with social, emotional and behavioural needs across the transition with a specific focus on the socio-emotional aspects of transition. This evaluative, mixed-methods case study took place in six clusters of primary/secondary schools in Scotland involving 63 pupils who participated within support groups for around $201 \mathrm{hr}$ sessions. It focuses on the accounts of Support Group Leaders, drawing from focus group discussions held within each cluster and a Likert scale questionnaire. A wide range of facilitators and barriers to implementation and to pupil progress were identified. Facilitators related principally to the quality of relationships and pedagogy which the support group afforded and the quality of support for the project. Barriers related principally to organisational and resource constraints and more general concerns around how behaviour support is perceived. The paper argues that supporting the transition for pupils with SEBN is complex and there is no 'magic bullet.' Building a supportive infrastructure from the outset is key to success. 
The mental health and wellbeing of children and young people is high on the international agenda (OECD, 2018). According to the OECD, a sense of wellbeing in children is correlated with a range of positive outcomes, including a greater sense of affiliation with school. Further, a sense of belonging to school is correlated with greater life satisfaction and improved academic outcomes (OECD, 2017a \& b \& 2018): 'the school environment, the level of student engagement, and the connectedness or relationships students have with their peers and teachers are all decisive factors of students' well-being' (OECD, 2018, p.3, citing Choi, 2018). Riley (2017) argues, 'the impact of teachers and of schools on the lives of young people cannot be underestimated. What happens to young people when they enter the school is likely to have a profound influence on their lives' (p.6). A range of factors, such as adverse childhood experiences, can impact on children's social and emotional development, but healthy relationships with parents and teachers can help to counteract this (OECD, 2018). Schools act as a protective factor in children's lives (World Health Organisation, 2016). However, the primary-secondary transition can serve to disrupt these relationships (Coffey, 2013) and the sense of belonging and connectedness to school which a child may have developed within the context of their primary school.

Supporting Positive Futures and Transitions is a group-work intervention developed by the author to support children who have been identified as having social, emotional and behavioural needs (SEBN), or at risk of such, as a means of promoting inclusive practice. The work has been supported by a research and development grant awarded by the Esmée Fairbairn Foundation to develop the approach beyond its initial setting - a secondary school in the West of Scotland - and to extend its reach to children in upper primary, spanning the transition to secondary school. This was accomplished through three projects -Secondary 2 (S2); Primary 6 (P6); and Transition, spanning Primary 7 (P7) and Secondary 1 (S1), undertaken within two Scottish local authorities. The focus of this specific article is the last 
of these - the Transition project - examined from the perspective of the staff within the school (principally Learning Support teachers) who led the support groups - Support group Leaders (Sg Leaders).

The transition from primary to secondary school presents as a time of new opportunities and challenge for children but which brings with it anxieties, fears and stresses (Lester, Waters, \& Cross, 2013; Riglin, Frederickson, Shelton, \& Rice, 2013; Topping, 2011; West, Sweeting, \& Young, 2010; Zeedyk et al., 2003). For children who may already be struggling with the day-to-day realities of school life, these anxieties, fears and stresses may be compounded. Schools focus on smoothing the academic transition to secondary school, attempting to avoid the universally recognised 'dip in attainment' following transition (Coffey, 2013; Hopwood et al., 2016; Mackenzie et al., 2012; Topping, 2011). Concerns about a lack of coherence, continuity and progression in curricula and pedagogy, associated with 'fresh start' approaches (Jindal-Snape \& Foggie, 2008), emerge (McGee et al., 2003) and are reflected in Scottish Government reports (HMIE, 2009, 2012). However, this features little in the accounts of parents and children who are much more focussed on the socioemotional aspects of transition (Jindal-Snape \& Foggie, 2008; Topping, 2011).

Whilst temporary exclusions from Scottish schools have significantly declined over the past decade (Scottish Government, 2018b), there are growing concerns about the behaviour of children in primary school, much of it relating to what might be described as low-level disruption (getting out of seat, making unnecessary noise), but there are more serious concerns about an increase in incidents of verbal abuse, physical aggression and physical violence towards teachers (Black, Eunson, Murray, Zubairi, \& Bowen, 2016). Further, the number of children temporarily excluded from Scottish schools for physical assaults using a weapon or an improvised weapon is at a five-year high (Scottish Government, 2018b). Early adolescence (McAra \& McVie, 2010) and the transition from 
primary to secondary school (Brewin \& Statham, 2011; Neal \& Yelland, 2014) can represent a critical period for children when they may either move in a positive or negative trajectory thereafter. As such, providing support to children who present in these ways across the transition from primary to secondary school is crucial yet there is little literature which focuses on the transition for children who have been identified as having, or being at risk of developing, SEBN.

\section{The Primary-Secondary Transition}

This part of the discussion will focus on the socio-emotional aspects of the primarysecondary transition for all children, culminating with a discussion of the importance of a sense of belonging and connectedness to school.

\section{Socio-emotional aspects of transition and children's mental health and wellbeing}

The transition from primary to secondary school represents for children both 'new possibilities' in which they can 'excel academically, socially, emotionally and in extra curricular activities' (Lester et al., 2013:15) and enjoy the new freedoms, varied curriculum, new learning experiences, new relationships and the opportunity for a 'fresh start' (Coffey, 2013; Hanewald, 2013; McGee et al., 2003). However, it is also a time of challenge as children adapt to new organisations and structures (Lester et al., 2013) and the relational and academic aspects of transfer (Coffey, 2013; Rice, Frederickson, \& Seymour, 2011). Pupils who experience a more positive transition report less loneliness, greater peer support and feelings of safety; and reduced feelings of anxiety, victimisation and peer problems (Waters, Lester, Wenden, \& Cross, 2012). Many commentators claim that anxieties relating to the transition process are often short-lived (Rice et al., 2011), however, West et al. (2010) find that the literature forwards contrasting perspectives on the degree to which concerns dissipate or grow after the initial period of transition. 
High quality best friend relationships have been identified as being a significant predictor of mental health and wellbeing (Kenny, Dooley, \& Fitzgerald, 2013) with higher levels of satisfaction related to lower levels of stress in adolescence. Gender differences in the quality of relationships between boys and those of girls were identified with girls enjoying more supportive relationships than boys, whilst, in contrast, boys reported higher levels of criticism. Girls also reported more support from their mothers (ibid.). As such, boys may have fewer supportive networks to act as a protective factor on the transition.

A range of authors draw attention to the 'transfer paradox' of children being 'big fish in a little pond', gaining status amongst their primary peers on going to the 'big school'(Mackenzie, McMaugh, \& O'Sullivan, 2012), but, in the process, becoming 'minnows in an uncharted ocean' (Topping, 2011: 270). The transition occurs at a time in which peer relations come to the fore as adolescents become more independent of their parents (Topping, 2011) and when children move from the more family-orientated primary school to the more impersonal environment of the secondary school (Coffey, 2013). Whilst many children looked forward to making new friends there were also anxieties around this (Mackenzie et al., 2012).

School related anxieties and the prevalence of bullying within the school environment can have a negative impact on pupils' wellbeing (OECD, 2017b; UNICEF Office of Research, 2016). Prior to transition, concerns about bullying are reported consistently in the literature (Jindal-Snape \& Foggie, 2008; McGee et al., 2003; Rice et al., 2011; Topping, 2011; West et al., 2010; Zeedyk et al., 2003) but the degree to which it is experienced posttransition is contested (West et al., 2010). Those children who experienced victimisation at the beginning of the transition were also more likely to experience it a year later indicating that the transition period may be a critical period of intervention to counter bullying (Waters et al., 2012). There are gender differences in how bullying is experienced by children across 
the transition, however, a sense of connectedness to the peer group and supportive friends during transition act as protective factors for both genders (Lester \& Cross, 2014). Whilst bullying behaviour declines over adolescence, boys were at the same risk of being victimised as girls but were more likely to be bullies or bully-victims than girls (Fanti \& Henrich, 2014).

It is suggested that bullying may, for some children, be an adaptation to the new environment in which they seek to manage peer and dominance relationships (Hanewald, 2013; Topping, 2011). It is regarded as one of the greatest sources of dissatisfaction for parents and children when not dealt with adequately by the school (Jindal-Snape \& Foggie, 2008). In contrast, Coffey (2013) found that bullying, post-transition, was not raised as a significant issue, attributed to the power of peer support programmes within the school, highlighting the important role which schools play in the primary-secondary transition.

\section{Sense of belonging and connectedness to school}

Riley (2017) argues for the significance of place and a sense of belonging in children's lives. A sense of belonging to the school community is correlated with a range of positive academic, psychological, behavioural and social outcomes for children and, conversely, a lack of a sense of belonging with a range of negative indicators leading to poor mental health, depression and anxiety (Prince \& Hadwin, 2013; Riglin et al., 2013). During transition when peer relationships can be disrupted and teacher relationships insecure (Coffey, 2013) this can be particularly of the essence. A caring school ethos and the promotion of positive relationships within the school act as protective factors (Prince \& Hadwin, 2013).

Bossaert, Colpin, Pijl, \& Petry (2013) also identify relationships and supportive networks, interactions with others, the child's self-perceptions and acceptance by classmates as being important variables in this regard. The teacher-pupil relationship is an important aspect in pupils' identification with school which, in turn, is correlated with greater pupil motivation (Tobbell and O'Donnell, 2013, citing Lizzio, Dempster and Neumann, 2011). 
However, perceptions of relationships with teachers emerged as an area which distinguished children with SEBN most from their well-behaved peers in the initial study conducted in a secondary school (Mowat, 2010) and Aldridge, Fraser, and Fozdar (2016) established that the influence of teacher support on students' wellbeing was negative.

A similar concept is that of 'school connectedness.' Its presence is associated with a range of positive adaptations and positive affect (such as happiness and positive self-esteem) but, conversely, its absence is related to a range of negative adaptations, affect and health compromising behaviours (such as early sexual activity), related to poor mental health outcomes (Lester et al., 2013). A positive and direct correlation has been estabished between school connectedness and children's life satisfaction and general sense of wellbeing, highlighting the importance of school and a positive school ethos in children's lives (Aldridge et al., 2016).

\section{The intervention}

Supporting Positive Futures and Transitions is a social-constructivist approach which aims to foster in children intrapersonal and interpersonal intelligences (Gardner, 1999). It is informed by the work of Professor David Perkins and his colleagues at Project Zero (Harvard University), particularly the body of work on teaching for understanding and for transfer.

The approach is delivered over $201 \mathrm{hr}$ sessions, spanning half a school year, for which pupils are extracted from classes to attend. The transition project spans the summer term in P7 and the autumn term in S1 and is delivered by two Support Group Leaders, one of whom supports the work of the children in the primary school and a further $\mathrm{SgL}$ who continues the work in the secondary school. However, to ensure continuity and progression in children's learning, the secondary Sg Leader works together with the primary Sg Leader in the period leading up to the transition. 
Pupils within the transition project were nominated and selected by class teachers and/or senior leaders within the school on the basis of two criteria: the pupil is having difficulty in coping with the norms of school of school life; and it is considered that the pupil might benefit from the approach. It should be noted that this is not a deficit position: it is recognised that there are many factors - some relating to the systems, structures, ethos and climate, curriculum etc. of the school - which may serve to disenfranchise children (Riley \& Rustique-Forrester, 2002; Riley, 2017). Pupils and parents were invited to the school to discuss the potential participation of the child within the study and had the opportunity to look at materials and raise any questions or issues prior to informed consent being sought.

Activities in which children engage are collaborative in nature and discussion-based and are designed to foster thinking skills and dispositions. An important aspect of the approach is target-setting by which children, with the guidance of their Sg Leader, set themselves weekly targets. The targets are monitored daily by the Sg Leader who meets with the children briefly each morning, by class teachers and by parents.

\section{Supporting implementation}

Six clusters of a secondary school and one or two of its Associated Primary schools took forward the study. Each cluster was led by a promoted member of staff within the secondary school who co-ordinated and supported the work of the cluster. The project team provided all pupil activities and materials for Sg Leaders, for school staff and for parents and created a website to support the work of the project. Sg Leaders attended four full-days of In Service training (INSET) and a representative of the senior leadership team from each participating school also attended a briefing session and was tasked with providing an input to all teaching staff within their schools. 


\section{Methodology}

\section{Research focus and aims}

This is an evaluative mixed-methods case study which is principally qualitative in design, constituting six clusters of schools across two local authorities in Scotland. It seeks to examine the efficacy of the approach, ascertain pupil outcomes, and the variables that impact on pupil outcomes to inform our understanding of the primary-secondary transition as it pertains to pupils with SEBN. It builds on a previous evaluative case study conducted within the single setting of a secondary school. Case study was considered the most appropriate approach as it allows for in-depth study of a phenomenon within its natural setting (Bassey, 1999; Flyvbjerg, 2011).

\section{The study design}

The study was designed such that each of the six clusters would take forward all three projects but what transpired was that only four of the clusters took forward the Transition project. Across the three projects, sixty-three support group pupils participated within the study, of whom seventeen were in the Transition project. The first phase of the study constituted the S2 and $\mathrm{P} 7$ projects with the transition project commencing six months later. A steering group was formed to ensure that a collaborative approach was adopted, constituting representation from the research team, the two local authorities and all Cluster Leaders. An highly experienced independent researcher acted in a consultancy role to the study and also participated within the steering group.

\section{Methods}

Focus Group Discussions were held in each of the six clusters with Support group leaders post-intervention. The focus group discussions were concerned with identifying the strengths and weaknesses of the approach and the variables that either acted to facilitate or impede pupil progress. Each focus group discussion took place in the secondary school and lasted for 
around $2 \mathrm{hrs}$. The discussions were framed around templates (cc. App 1) that were placed on a flipchart and completed by a member of the research team to capture the main elements of the discussion. The discussions were also recorded and transcribed.

Prior to participating within the focus group discussions, the Sg Leaders carried out a de-briefing exercise with pupils during the last meeting of the support group focussing on what pupils had learned through participation and how they considered that they had changed (cc. App 2). This was followed by individual interviews conducted by the Sg Leader with each pupil based on an interview schedule (constructed by the research team in consultation with Sg Leaders) that explored similar questions. The research team provided training in conducting the interviews through role-play. The interviews were regarded as an integral aspect of the intervention as a means of helping pupils to reflect on their learning but also providing feedback to the Sg Leaders which then informed the report to parents. Parents were invited to comment on the child's progress. All of the above, and feedback from the targetsetting process, informed the perspective of Sg Leaders, feeding into the focus group discussions.

Likert Scale Questionnaire derived from a modification to the Scottish Government's tool for self-evaluation of schools - 'Journey to Excellence' (HMIE, 2006) - was also completed by each of the twenty-six Sg Leaders (cc. App 3).

\section{Data analysis}

Qualitative data were analysed by means of thematic analysis (King \& Horrocks, 2010). After reading over the transcripts, passages which directly addressed the research questions were highlighted and the review function was used to write descriptive comments, précising the passages. Thereafter descriptive codes were derived and these were then applied across the data-set as a whole. This is a complex, iterative process, moving backwards and forwards across the data set until a point of saturation is reached. The descriptive codes were then 
removed from the data source and classified and sorted to generate analytical codes and this process was repeated to generate over-arching themes. The codes and themes generated were triangulated with the bullet points captured on the templates, ensuring trustworthiness.

Quantitative data deriving from the analysis of the questionnaires were entered into Qualtrics (an online survey tool) and analysed via. descriptive statistics, establishing the mean response for each measure.

\section{Findings}

\section{'Journey to Excellence' questionnaire}

When examining responses to the 10 dimensions and 41 measures (cc. App 3 \& figures $1 \&$ 2), it is clear that Sg Leaders valued many different aspects of the project, from those relating to the quality of pedagogy; the affordances for pupils; aspects of the project design and delivery; and the affordances of the approach across the school as a whole in fostering inclusive practice. Supporting Positive Futures and Transitions had not only been beneficial for pupils but also for Sg Leaders in terms of developing their expertise and providing opportunities for them to exercise leadership within the school - it had empowered both staff and pupils and given pupils a sense of 'what can be'.

The two areas which emerged as requiring further development related to the extent to which the approach had fostered partnerships between the two participating local authorities; between clusters; and with external agencies (the degree to which Educational Psychologists supported implementation varied across clusters); and the degree to and ways in which parents had engaged with and been involved with the project.

$$
\begin{aligned}
& \text { Insert Figure } 1 \text { (landscape) } \\
& \text { Insert Figure } 2 \text { (landscape) }
\end{aligned}
$$




\title{
Focus Group Discussions
}

This discussion is derived from the focus group discussions conducted within the four clusters which took forward the transition project. Table 1 summarises the key themes to emerge, classified according to affordances and constraints to pupil progress.

Please insert table 1

\section{The value of the intervention in supporting the primary-secondary transition}

\section{Relational Aspects}

A key aspect of the approach for Sg Leaders was the opportunity that the support group afforded in building trusting relationships between staff and pupils across the transition. It provided a more intimate forum in which the pupil and prospective Sg Leader could get to know each other, giving the pupil a friendly face and someone to go to if they had concerns or problems post-transition:

\footnotetext{
Erm, when I read, I took home the pack that was sent out and I read through it and thought this, this sounds perfect for XXX because of the transition element to it. And I, I've always worried what XXX is going to be like when he moves to ...the high school. So starting something in P6, would, would really help him .. if it could build up a trust with a High School teacher...
}

Sg Leader P6, FG Cluster

Giving children a voice, being listened to and cared about within a safe environment in which children could talk about things that were important to them were considered as being key aspects of the approach:

\begin{abstract}
...we were able to give these children quality time and they could see that you were actually interested in them and that you were willing to listen and they weren't holding back any information... It's also giving the children the opportunity to see that they matter .... and being able to take that luxury of time to speak to them about it (their behaviour).
\end{abstract}

Sg Leader P6, AH Cluster

It was generally felt that the support group offered a means of smoothing and facilitating the transition process for pupils: 
I thought it was extremely positive for all the children, and the children I worked with who were having exceptional difficulties down at the primary school didn't seem to have any difficulties when they came up to the big school.

Sg Leader Transition (S1), AF Cluster

It articulated well with the other mechanisms that the schools adopted to promote the transition process, building on established good practice.

\section{Pedagogical Aspects}

The approach was considered to offer a structured, progressive approach to learning, offering continuity of support across the transition:

Because often wi' the very challenging ones, you're looking at ways for that transition to, not to have a hiccup in the middle in terms a' the support that's being offered and this methodology would let you have that transition because the, the resources would be structured.

Sg Leader P6 and Transition (P7), AF Cluster

The focus on teaching for understanding was identified as being an important aspect in furthering children's learning:

It's not reading and writing. It's 'why am I being angry?' And it's actually explaining why you might be being angry or why you might be considering to behave in this certain manner. And it's almost like, when you were talking to the children, light bulbs were going on in their head. And they just think, 'Gosh I know what I'm doing, you know, I know why I'm doing it.'

Sg Leader Transition (S1), AF Cluster

It offered an interactive, informal discussion-based pedagogy which was open-ended and exploratory, offering freedom to explore ideas. The approach was considered to be inclusive, linking to the child's value and belief system. It was flexible and responsive to pupil needs, accommodating the learning pace of children. It was a just approach enabling pupils to take responsibility for their own behaviour.

However, not all pupils engaged as well as they might. In one cluster, there was a difficult group dynamic and it was difficult to get boys to engage. It was also mooted that pupils needed a degree of emotional intelligence to be able to engage within the activities and 
discussions and that there could be a degree of insincerity in pupil responses. For some pupils, it was considered that a longer intervention period was required.

\section{Impacts for pupils}

There were many positive impacts for pupils as will be illustrated in the accounts to follow but also illustrated in the responses to the 'Journey to Excellence' questionnaire (cc. App 3).

\section{Working collaboratively together to support the transition}

As previously intimated, the study had been designed around clusters of schools to facilitate implementation and the sharing of good practice. Within one cluster not only had the staff met very regularly to share their practice and support each other, they had also worked in teams to lead groups for all three projects when this proved to be possible. This had been highly beneficial not only to staff but for pupils: 'Good having two adults there' (Sg pupil, AI Cluster). Staff on the transition project really valued the help, support and insights from other Sg Leaders who had led P6 and S2 support groups: '.. a great thing for myself was that Mrs XXX [Sg Leader P6], had been through the process and we worked together a lot and shared ideas, so that was great' (Sg Leader Transition (P7), FD Cluster).

The contribution of the secondary transition Sg Leader in the period leading up to the transition had been appreciated:

\footnotetext{
... having someone from the Academy come down and be in the group with us and to hear, because I don't think they believed it so much from us. Whereas to hear it from XXX, it was a really, it was really good and really positive.
}

\section{Sg Leader Transition (P7), AI Cluster}

However, on a more cautionary note, one Sg Leader drew to attention the differing philosophical positions of primary and secondary teachers in working with children which led to discontinuities in practice, highlighting the need for Sg Leaders to meet independently of the group to come to a shared understanding. 


\section{Support for the project}

The inclusive and collaborative approach adopted by the research team, the enthusiasm of the Project Leader and the quality of planning and organisation were cited as positive aspects of the project. Important facilitators of the project were: effective communication channels, such as direct contact between the cluster Leaders and the Project Leader; the role which the Cluster Leader played as an intermediary between the research team and staff on the ground; timeous responses to queries; information and downloadable materials on the website; regular newsletters updating people of progress with hyperlinks to the website; the linkages between the local authority, cluster leaders and the research team facilitated through the steering group; and the building of partnerships between secondary and primary schools within the cluster.

In-Service training for Sg Leaders was considered to be of a high quality, enabling $\mathrm{Sg}$ Leaders to familiarise themselves with the materials, facilitating the building of relationships and networking, building on the previous experience and expertise of staff and fostering their professional development. However, the scheduling of INSET days could be problematic.

\section{A Tale of Two Clusters}

Whilst, in general, experience of the transition project had been very positive, there were significant differences across clusters as illustrated within this 'Tale of two Clusters.'

\section{Cluster FD}

In this specific cluster, the transition project was regarded as the most successful of the three projects: 'And I think the transition part has been particularly positive and I think the younger we get them to work with them probably the more success we'll have, I would imagine' (Cluster Leader, FD Cluster). The Sg Leader who was to lead the group in the secondary 
school participated within the support group in the primary school and felt that it had enabled her 'to get to know the pupils, their strengths and a side to their behaviour which would not be obvious in a whole class setting' (Sg Leader Transition (S1), FD Cluster). She worked with the group for a further 10 weeks after transition to secondary school, maintaining the continuity of the group. She felt that pupils were quite open within the group and were able to talk freely in a non-judgemental setting. They had a sense of achievement when their targets were reached and they had developed the problem-solving skills to be able to ascertain why they had not been successful, on occasion, in reaching their goals. Through this, she felt that they were more aware of making good choices, thought through their behaviour in context and had gained in self-esteem.

The Sg Leader who had led the primary support group had also had a positive experience. For her, the main strengths of the approach were that it was non-judgemental and resonated with restorative practice; provided opportunities for children to open up about their feelings in a safe environment; gave children 'a voice' and promoted pupil agency; and helped children to see that they weren't alone - 'they could see commonalities within themselves and others in the group.' The programme itself she described as flexible and responsive to children's needs; the activities related well to children's everyday experiences; and the suggested targets were appropriate to the needs of the children.

\section{Cluster FG}

In the other cluster, the experience of transition had been less positive. Pupils had responded well within the primary school and in the first few weeks of transition but thereafter had rejected the approach.

I think initially it was a relief for them to see somebody that they knew, and for the first couple of sessions, when they were settling into XXX High School, that they were quite eager to come and they would sit and tell you how they got on. As they settled in themselves that is when things 
began to get more difficult as they decided they weren't going to be engaging as much as maybe we had hoped they would.

Sg Leader Transition (S1), FG Cluster

Due to staffing constraints and a change of circumstance within the primary school, there had been a lack of fidelity to the approach and the opportunities for the Sg Leaders to work together had been limited. The secondary transition Sg Leader had only been able to join the group once prior to transition. She had found it difficult to step into the programme mid-way as she felt that she didn't have the in-depth knowledge of the children that she would have liked nor had she been able to establish a relationship with them prior to transition.

Despite their initial positive engagement, the pupils began to feel uncomfortable about being extracted from class to attend the support group and presenting their target booklets to their class teachers. They didn't want to miss the lessons from which they were extracted (the last of these considered to be a timetabling issue). They began to feel 'singled out.' It wasn't the support group itself nor the activities within it which concerned them - it was more about how their participation would be perceived by others:

\footnotetext{
... because people would start to ask them, "Why are you going with Mrs XXX?" "What is this all about?" and that is when it sort of came ... I think if that had been taken away it would have worked quite well. But it was how others had perceived them coming out that was more of a problem than them themselves.
}

Sg Leader Transition (S1), FG Cluster

This is of real concern, particularly in early adolescence when issues of identity come to the fore (Symonds, 2015). Target setting had proved to be an important motivator for many children but whilst the processes associated with it can be handled unobtrusively in primary school, it is more difficult to achieve this in secondary school. Guidance was offered to schools as to how to ameliorate this difficulty with a range of alternative suggestions offered. 


\section{Organisational Aspects of the Transition Project}

The Transition project is ambitious and makes demands on resources at a time when there are known staff shortages in Scottish education and pressures of workload (Scottish Government, 2018a). There was a lot of new information to impart and for staff to digest although every effort was made to minimise this. Constraints of the timetable in secondary schools make it difficult to extract children for support (of any kind) without it adversely affecting their learning, therefore, there needs to be a very careful balance maintained in terms of the potential costs and benefits to children. The flexibility afforded by Curriculum for Excellence should offer schools opportunities to examine more imaginative and flexible timetabling solutions to minimise potential stigmatisation and labelling.

An issue to emerge was the timing of the intervention over the summer term in primary schools when there is a range of competing imperatives, '...you walk in and they've got sports day and you walk in and they've got a play' (Sg Leader Transition (S1) and S2, AI Cluster), leading to a lack of continuity. An earlier start to the Transition project was considered within this cluster to be more beneficial as it would provide more opportunity for the learning to be internalised prior to transition.

\section{Commitment from the Local Authority and School Leadership team}

The commitment and support of the two local authorities were essential in facilitating the project. They provided resources (such as accommodation) and played a key role within the steering groups, making it clear that the local authority was fully behind the project. Factors which emerged as crucial facilitators of the approach were: high quality leadership at all levels of the school, encompassing the support and direction from the headteacher and senior leadership team, prioritising the project and affording time and resources for it; the commitment, enthusiasm, motivation and expertise of Sg Leaders; and the willingness of staff within the school to engage with the target-setting process. This is dependent on a 
positive school climate and ethos. However, when support from the senior leadership team was not maintained within one cluster, this led to communication difficulties and a sense of impotence in Sg Leaders.

\section{Partnerships with parents}

Partnerships with parents emerged as both an affordance and a constraint. When parents were involved and engaged, particularly in supporting the target-setting process through positive encouragement, this was an important motivator for children. However, this did not always prove to be the case and support was considered to be variable.

\section{Discussion}

As previously intimated, an emerging theme within the literature is the importance of a sense of belonging and connectedness to school (Lester \& Cross, 2014; Prince \& Hadwin, 2013; Riglin et al., 2013) with regard to children's mental health and wellbeing and this is particularly important for pupils who might be considered to be vulnerable on the transition to secondary school, particularly when relationships are in a state of flux (Coffey, 2013) and more difficult to form within the complex and more formal organisational structures of the secondary school (Jindal-Snape \& Miller, 2008; West et al., 2010). Many of the affordances of the approach for pupils, such as being listened to, affirmed and included, and valued for who you are, clearly resonate with this, acting to facilitate the transition and making it less likely that children would experience the deleterious effects associated with anxiety, stress and bullying, as described by a range of authors (Jindal-Snape \& Foggie, 2008; Kenny, Dooley, \& Fitzgerald, 2013; McGee, Ward, Gibbons, \& Harlow, 2003; Rice et al., 2011; Topping, 2011; Waters et al., 2012; Zeedyk et al., 2003).

Aldridge et al. (2016), draw attention to the importance of having a supportive adult that the child can go to when they have concerns or problems but there are few interventions 
focusing on the socio-emotional development of children which span both the primary and secondary school that enable the formation of trusting relationships between children and adults which would facilitate this. Symonds (2015) analyses fourteen studies of the primarysecondary transition delivered to either children or parents, four of which were delivered within the setting of the primary school and the remainder of which were all delivered after the transition within the setting of either the middle school or high school. None spanned the transition. Whilst programmes such as induction days and summer schools seek to smooth the transition for pupils, Symonds identifies that they often give a misleading (and over optimistic sense) of what schooling would be like post-transition, leading to a sense of disappointment when this does not subsequently transpire (ibid.). This contrasts with the support group approach which, according to Sg Leaders, offers genuine continuity and progression across the transition in support and learning.

Universal themes to emerge from the literature on leadership and change management are the importance of developing collaborative forms of leadership (Ainscow, Booth, \& Dyson, 2006; MacBeath, Dempster, Frost, Johnson, \& Swaffield, 2018) and building a shared vision and values across the school community (Coates, 2017). Such a vision cannot be imposed and is dependent on building shared understandings which, in turn, is dependent on investing in staff and high quality INSET, or as Hargreaves and Fullan (2012) argue, investing in capability and commitment. However, tensions around how inclusion is understood can lead to differing interpretations as to what equates to inclusive practice. For some, any removal of a child from the setting of the classroom for additional support may be seen as exclusionary, no matter the long-term objective. Within the wider study, this emerged as a tension for Sg Leaders (and how their work was perceived within the school) (Mowat, 2015) and may explain why this specific measure on the questionnaire was rated less 
positively than might have been expected, given that the principal focus of the work is to promote inclusive practice.

Given the potential for stigmatisation and labelling which may occur when children are extracted from class for additional support (of any kind), it could be argued that the work might best be tackled through a universal approach, offered to all pupils. However, it is evident from examining the affordances of the approach that it is the intimate setting of the group which enabled many of the positive outcomes for children. Within a setting in which all children are valued for who they are (Khon, 2005) (related to Carl Rogers' concept of unconditional positive regard (Bozarth, 2007)); in which diversity is positively celebrated; and in which there is a focus on children's rights and wellbeing, there is less likelihood of children being stigmatised if they require support additional to that which can be offered within the setting of the mainstream classroom and this requires strong direction from senior leadership in setting the climate and tone within the school.

As previously discussed, Sg Leaders across the study as a whole identified strong synergies between the support group approach and other approaches towards promoting positive behaviour which focus on relationship building, developed concurrently within the clusters - restorative practice, rights respecting schools and nurture. It can also be seen that it is the efforts of all - the pupils themselves, their peers, the wider school community and family supports - which ultimately make a difference for pupils, stressing the importance of partnerships with parents and a collaborative approach in taking the work forward. Yet, Harris and Goodall (2008) highlight that this can be challenging as some parents are reluctant or unable to work in partnership with schools, influenced by context and culture, which can be incorrectly interpreted as either resistance or intransigence. As the authors state, parents need to know that they matter. Buchanan and Buchanan (2017) highlight key aspects of building meaningful parental engagement including the importance of knowledge of the child 
and family; a shared commitment to the child's well-being and success; a strengths based (rather than a deficit) perspective; and building trust and reciprocal communication. Parental engagement therefore needs to be central to what schools do and not peripheral. Although genuine attempts were made within the study to engage with parents at all of the different stages of the project, the degree to which this happened varied from cluster to cluster, highlighting this as an area requiring further development.

\section{Conclusion}

What this study has established is that supporting the transition for pupils with social, emotional and behavioural needs is complex. There is no 'magic bullet' which can be guaranteed to bring success for each and every pupil as how pupils experience the transition is unique to them. The affordances and constraints of the support group as a means of supporting the primary-secondary transition played out in different ways in different settings, contexts and circumstances and it was often a matter of balance - did the perceived benefits outweigh the potential disadvantages for individual children?

What makes this particularly complex is that there is no means of anticipating how an individual child might respond and, as illustrated in Cluster FG, responses to intervention may change over time and changing circumstances. Therefore, it is a difficult judgement call but there are also dangers in not acting. Kauffman (2013 \& 2014) is concerned that a failure to act in the absence of severe difficulties in childhood may eventually lead to more severe disorders in adulthood. For him, early intervention (as a preventative measure) makes infinite sense both as a moral and an economic imperative. However, many professionals reject early intervention on a range of grounds, such as concerns about potential labelling and stigma (not recognising that many such children have already attracted derogatory informal labels by professionals and peers - 'waste of space,' 'troublemaker,' 'loonie') (Kauffman, 2013 \& 
2014; Mowat, 2015); and an over-optimistic sense that children will 'grow out of it'

(Kauffman, 2014), amongst other issues.

The staged intervention approach adopted in Scottish schools often means that, by the time a child receives specialist support (if it is offered at all), their difficulties (no matter their provenance) have become so entrenched that they may be intractable. The data from the Scottish Government indicating that SEBN is a growing problem in Scottish schools should act as a 'shot across the bows' and, particularly within the context of addressing the attainment gap associated with poverty (Scottish Government, 2016), it is crucial to support children from the very first signs of difficulty in coping with the norms of school life and particularly at times (such as transition) which, as previously intimated, can be a 'critical period' for children's socio-emotional development.

\section{Funding Statement}

This study has been supported by the Esmée Fairbairn Foundation: Project 10-0777.

\section{References}

Ainscow, M., Booth, T., \& Dyson, A. (2006). Improving Schools, Developing Inclusion. London: Routledge.

Aldridge, J. M., Fraser, B. J., \& Fozdar, F. (2016). Students' perceptions of school climate as determinants of wellbeing, resilience and identity. Improving Schools, 19(1), 5-26. doi: $10.1177 / 1365480215612616$

Bassey, M. (1999). Case Study in Educational Settings. Oxford: Oxford University Press.

Black, C., Eunson, J., Murray, L., Zubairi, S. S., \& Bowen, L. (2016). Behaviour in Scottish Schools Research 2016. Scottish Government [on behalf of Ipsos MORI Scotland] Retrieved from http://www.gov.scot/Publications/2017/11/5792.

Bossaert, G., Colpin, H., Pijl, S. J., \& Petry, K. (2013). Truly included? A literature study focusing on the social dimension of inclusion in education. International Journal of Inclusive Education 17 (1): 60-79.

Bozarth, G. (2007). Unconditional Positive Regard. In M. Cooper, M. O'Hara, P. F. Schmid \& G. Wyatt (Eds.), The Handbook of Person-Centred Psychotherapy and Counselling (pp. 182-193). New York: Palgrave Macmillan.

Brewin, M., \& Statham, J. (2011). Supporting the transition from primary school to secondary school for children who are Looked After. Educational Psychology in Practice: theory, research and practice in educational psychology 27(4): 365-381. 
Buchanan, K., \& Buchanan, T. (2017). Relationships with families: Have educators overlooked a critical piece of the puzzle? Improving Schools, 20(3), 236 -246. doi: $10.1177 / 1365480216674622$

Choi, A. (2018). Emotional well-being of children and adolescents: recent trends and relevant factors, OECD education working papers, No. 169. OECD Publishing, Paris.

Coates, M. (2017). Setting direction: Vision, values and culture. In P. Earley \& T. Greany (Eds.), School Leadership and Education System Reform (pp. 90-99). London: Bloomsbury.

Coffey, A. (2013). Relationships: The key to successful transition from primary to secondary school? Improving Schools 16(3): 261-271.

Fanti, K.A., and C.C. Henrich. (2014). Effects of Self-Esteem and Narcissism on Bullying and Victimization During Early Adolescence. Journal of Early Adolescence 35(1): 5 29. doi: $10.1177 / 0272431613519498$.

Flyvbjerg, B. (2011). Case Study. In N.K. Denzin and L. Lincoln (Eds.), The SAGE Handbook of Qualitative Research (Sage Handbooks (pp. 301-316). London: SAGE Handbooks.

Gardner, H. (1999). Intelligence Reframed: Multiple Intelligences for the 21st Century. New York: Basic Books.

Hanewald, Ria. (2013). Transition Between Primary and Secondary School: Why it is Important and How it can be Supported. Australian Journal of Teacher Education. 38 (1): $62-74$.

Hargreaves, A., \& Fullan, M. (2012). Professional Capital: Transforming Teaching in Every School. London: Routledge.

Harris, A., \& Goodall, J. (2008). Do parents know they matter? Engaging all parents in learning. Educational Research and Reviews. 50(3), 277-289. doi: $10.1080 / 00131880802309424$

HMIE. (2006). How good is our school? The Journey to Excellence. Edinburgh: Her Majesty's Stationery Office.

HMIE. (2009). Quality and Improvement in Scottish Education: trends in inspection findings 2005-2008. Edinburgh: Scottish Government.

HMIE. (2012). Quality and Improvement in Scottish Education: trends in inspection findings 2008-2011. Edinburgh: Scottish Government.

Hopwood, B., Hay, I. \& Dyment, J. (2016). The transition from primary to secondary school: Teachers' perspectives. Australian Educational Researcher 43(3), 289-307. doi:10.1007/s13384-016-0200-0.

Jindal-Snape, D. \& Foggie, J. (2008). A holistic approach to primary-secondary transitions. Improving Schools 11(1): 5-18.

Jindal-Snape, D. \& Miller, D. (2008). A Challenge of Living? Understanding the Psychosocial Processes of the Child During Primary-secondary Transition Through Resilience and Self-esteem Theories. Educational Psychology Review. 20: 217-236.

Kauffman, J., M. (2013). Labeling and categorizing children and youth with emotional and behavioral disorders in the USA: Current practices and conceptual problems. In J. Visser, H. Daniels \& C. Cole (Eds.), The Routledge International Companion to Emotional and Behavioural Difficulties [Routledge Handbook] (pp. 15-21). London: Routledge.

Kauffman, J. M. (2014). How we prevent the prevention of EBD in education. In P. Garner, J. M. Kauffman \& J. Elliot (Eds.), The SAGE Handbook of Emotional and Behavioural Difficulties (2nd ed.) (pp. 13 -21). London: SAGE.

Kenny, R., Dooley, B., \& Fitzgerald, A. (2013). Interpersonal relationships and emotional distress in adolescence. Journal of Adolescence, 36(2), 351-360. 
Khon, A. (2005). Unconditional Teaching. Educational Leadership, 63(1), 20-24.

King, N., \& Horrocks, C. (2010). Interviews in Qualitative Research. London: SAGE.

Lester, L., \& Cross, D. (2014). Do emotional and behavioural difficulties in primary school predict adolescent victimisation trajectories? Emotional and Behavioural Difficulties, 19(4), 356-370.

Lester, L., Waters, S., \& Cross, D. (2013). The Relationship Between School Connectedness and Mental Health During the Transition to Secondary School: A Path Analysis. Australian Journal of Guidance and Counselling, 23(2), 157-171.

MacBeath, J., Dempster, N., Frost, D., Johnson, G., \& Swaffield, S. (2018). Strengthening the Connections between Leadership and Learning: Challenges to Policy, School and Classroom Practice. London: Routledge.

Mackenzie, E., McMaugh, A., \& O'Sullivan, K-A. (2012). Perceptions of primary to secondary school transitions: Challenge or threat? Issues in Educational Research, 22(3), 298-314.

McAra, L., \& McVie, S. (2010). Youth crime and justice: Key messages from the Edinburgh Study of Youth Transitions and Crime. Criminology and Criminal Justice, 10(2), 179209.

McGee, C., Ward, R., Gibbons, J., \& Harlow, A. (2003). Transition to Secondary School: A Literature Review: Ministy of Education, New Zealand.

Mowat, J. G. (2010). "He comes to me to talk about things": supporting pupils experiencing social and emotional behavioural difficulties - a focus upon interpersonal relationships. Pastoral Care in Education, 28(3), 163-180.

Mowat, J. G. (2015). 'Inclusion - that word!' examining some of the tensions in supporting pupils experiencing social, emotional and behavioural difficulties/needs. Emotional and Behavioural Difficulties, 20(2), 153-172.

Neal, G., \& Yelland, N. (2014). (Dis)advantage and (Dis)engaged: Reflections from the First Year of Secondary School in Australia. Journal of Education and Learning, 3(3), 114. doi: ISSN 1927-5250.

OECD. (2017a). PISA 2015 Results (Volume III): Students' Well-Being. Paris: OECD.

OECD. (2017b). Are students happy? PISA 2015 Results: Students' Well-being, Vol 3. In PISA in Focus. Paris: OECD.

OECD. (2018). Trends Shaping Education Spotlight 14: Good vibrations: Students' wellbeing. Paris: OECD.

Prince, E. J., \& Hadwin, J. (2013). The role of a sense of school belonging in understanding the effectiveness of inclusion of children with special educational needs. International Journal of Inclusive Education, 17(3), 238-262.

Rice, F., Frederickson, N., \& Seymour, J. (2011). Assessing pupil concerns about transition to secondary school. British Journal of Educational Psychology. 81 (2), 244-263.

Riley, K.A. \& Rustique-Forrester, E. (2002). Working with Disaffected Students. London: Chapman Publications.

Riley, K. (2017). Place, belonging and school leadership: researching to make the difference. London: Bloomsbury Academic.

Riglin, L., Frederickson, N., Shelton, K. H., \& Rice, F. (2013). A longitudinal study of psychological functioning and academic attainment at the transition to secondary school. Journal of Adolescence, 36(3), 507-517.

Scottish Government. (2016). National Improvement Framework for Scottish Education: Achieving excellence and equity Retrieved from http://www.gov.scot/Publications/2016/01/8314. 
Scottish Government. (2018a). Evaluation of the Attainment Scotland Fund Interim Report (Years 1 and 2). Retrieved from http://www.gov.scot/Publications/2018/03/1892/351438.

Scottish Government. (2018b). School Exclusions 2016/2017. Edinburgh: Scottish Government.

Symonds, J. (2015). Understanding School Transition: What happens to children and how to help them. London: Routledge.

Tobbell, J. \& O'Donnell, V.L. (2013). The Formation of Interpersonal and Learning Relationships in the Transition from Primary to Secondary School: Students, Teachers and School Context. International Journal of Educational Research 59, 11-23.

Topping, K. (2011). Primary-secondary transition: Differences between teachers' and children's perceptions. Improving Schools, 14(3), 268-285.

UNICEF Office of Research. (2016). Fairness for Children: A league table of inequality in child well-being in rich countries. UNICEF Innocenti Report Card 13. Florence: UNICEF Office of Research - Innocenti.

Waters, S. K., Lester, L., Wenden, E., \& Cross, D. (2012). A Theoretically Grounded Exploration of the Social and Emotional Outcomes of Transition to Secondary School. Australian Journal of Guidance and Counselling, 22(2), 190-205

West, P., Sweeting, H., \& Young, R. (2010). Transition matters: pupils' experiences of the primary-secondary school transition in the West of Scotland and consequences for well-being and attainment. Research Papers in Education, 25(1), 21-50.

World Health Organisation. (2016). Growing up unequal: gender and socioeconomic differences in young people's health and well-being: Health Behaviour in SchoolAged Children (HBSC) Study: International Report from the 2013/2014 survey. Denmark: WHO.

Zeedyk, M. S., Gallacher, J., Henderson, M., Hope, G., Husband, B., \& Lindsay, K. (2003). Negotiating the Transition from Primary to Secondary School: Perceptions of Pupils, Parents and Teachers. School Psychology International, 24(1), 67-89. 


\section{Figure 1}

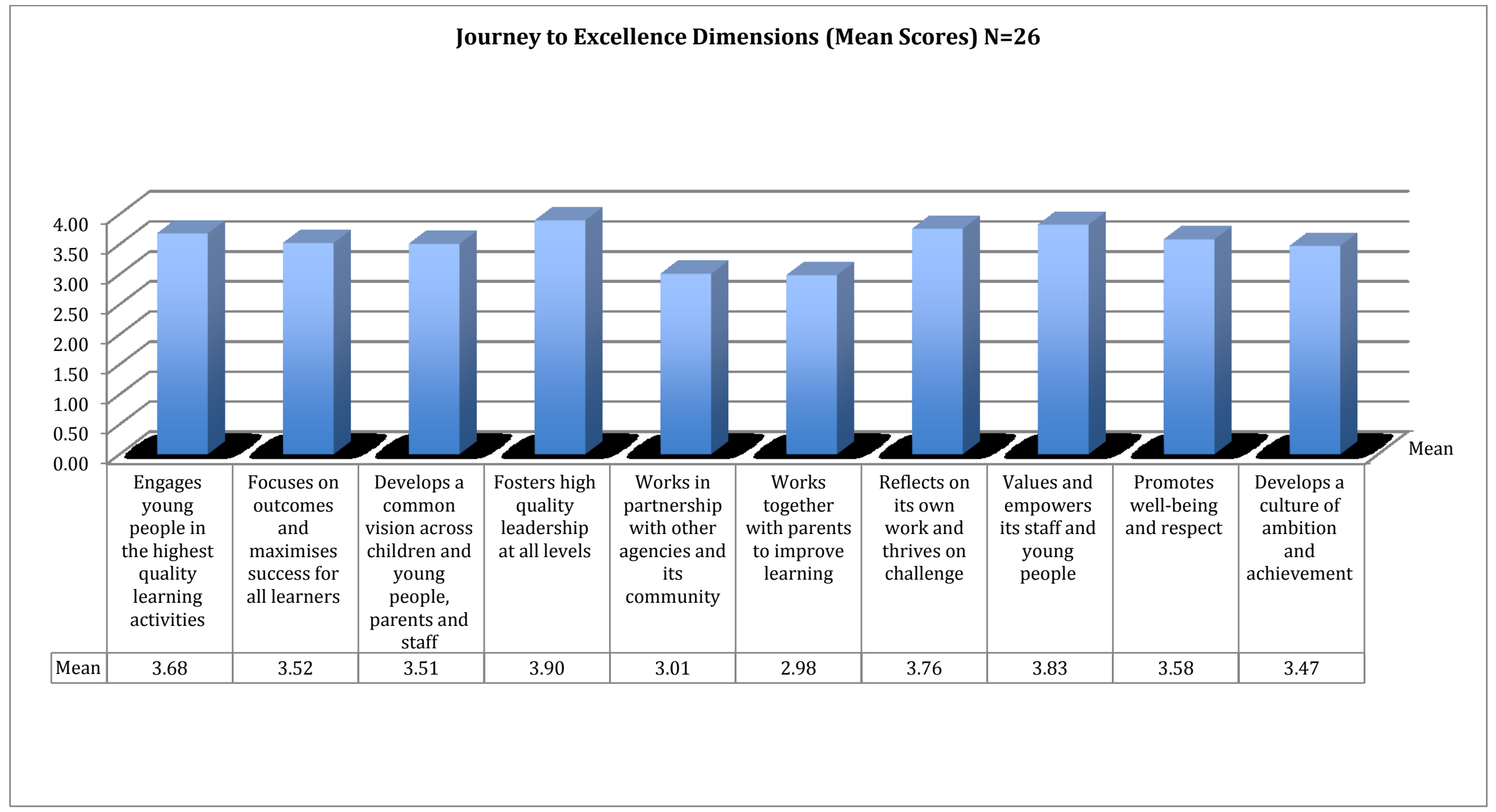

Rating Scale: $1=$ poor; 2 = fair; $3=$ good; 4 = very good; 5 = excellent.

Figure 1: Sg Leader responses to the questionnaire modified from 'Journey to Excellence' (Her Majesty's Inspectorate of Education 2006) 
Figure 2

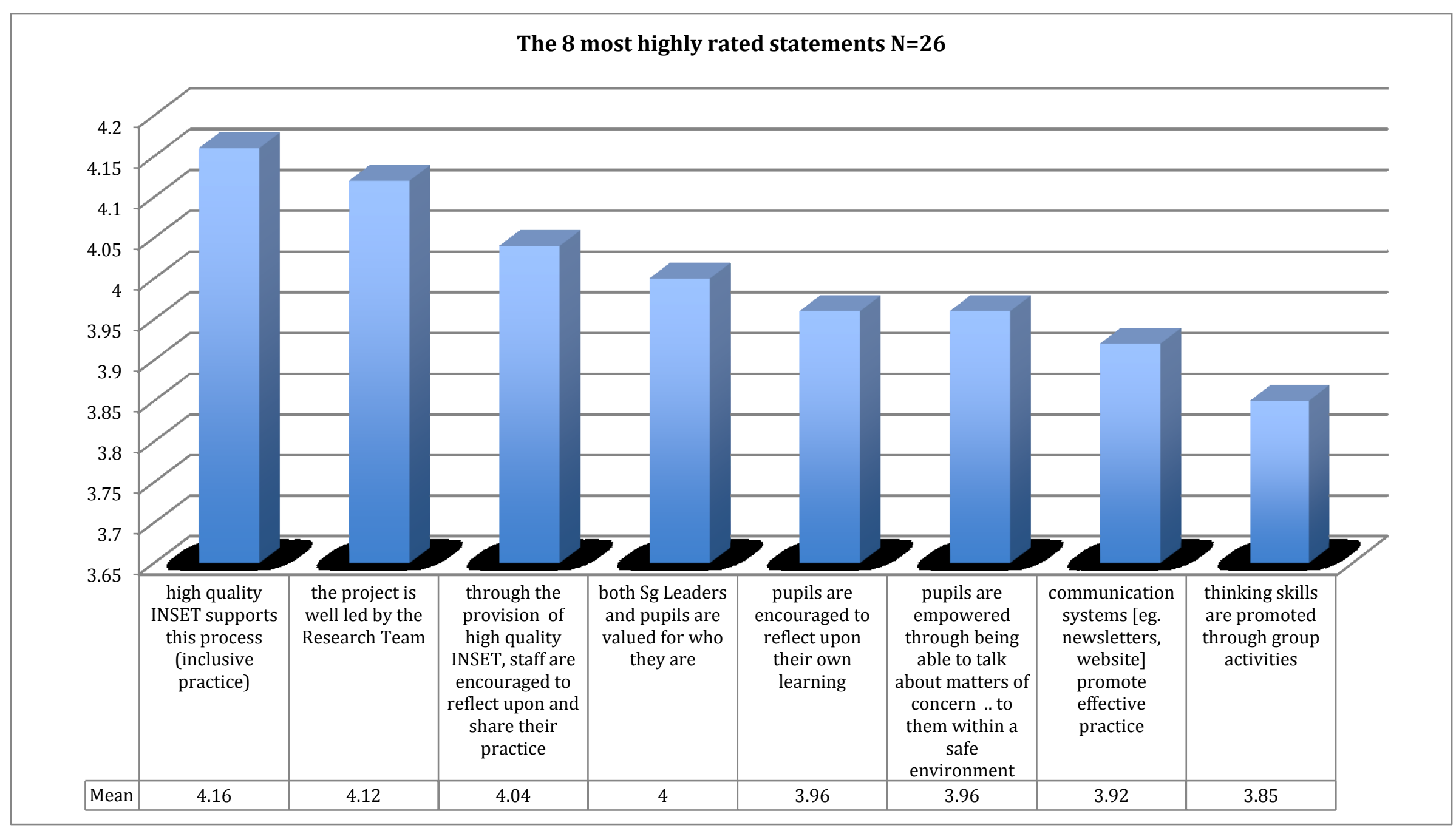

Rating Scale: $1=$ poor; 2 = fair; $3=$ good; $4=$ very good; $5=$ excellent.

Figure 2: Sg Leader responses to the questionnaire modified from 'Journey to Excellence' (Her Majesty's Inspectorate of Education 2006) 
Table 1

\begin{tabular}{|c|c|c|}
\hline Themes & Affordances & Constraints \\
\hline \multirow[t]{3}{*}{ About the approach } & $\begin{array}{l}\text { Relational } \\
\text { eg. building trusting relationships } \\
\text { between staff and pupils and with } \\
\text { parents across the transition }\end{array}$ & $\begin{array}{l}\text { Relational } \\
\text { eg. difficulties in getting boys to } \\
\text { engage (specific to one support } \\
\text { group) }\end{array}$ \\
\hline & $\begin{array}{l}\text { Pedagogy, Curriculum } \\
\text { eg. inclusive approach linking to } \\
\text { values and beliefs }\end{array}$ & $\begin{array}{l}\text { Pedagogy, Curriculum } \\
\text { eg. organisational aspects of target- } \\
\text { setting proved to be difficult for } \\
\text { some children }\end{array}$ \\
\hline & $\begin{array}{l}\text { Positive Impacts for pupils } \\
\text { eg. facilitating understanding in } \\
\text { children of themselves and their } \\
\text { relationships with others }\end{array}$ & $\begin{array}{l}\text { Negative impacts for pupils } \\
\text { eg. extraction from class leading to } \\
\text { pupils missing aspects of the } \\
\text { curriculum }\end{array}$ \\
\hline \multirow[t]{6}{*}{$\begin{array}{l}\text { Related to project design, } \\
\text { the management aspects of } \\
\text { the project, support for staff } \\
\text { and the approach of the } \\
\text { project team }\end{array}$} & $\begin{array}{l}\text { A collaborative approach within } \\
\text { clusters } \\
\text { eg. mutual support within clusters }\end{array}$ & $\begin{array}{l}\text { Demands of the Project \& } \\
\text { Organisational Aspects } \\
\text { eg. the time commitment required } \\
\text { of staff, including daily monitoring } \\
\text { of pupils }\end{array}$ \\
\hline & $\begin{array}{l}\text { Communication and Project } \\
\text { Design } \\
\text { eg. the Cluster Leader acting as an } \\
\text { intermediary between the research } \\
\text { team and SG Leaders within the } \\
\text { cluster }\end{array}$ & $\begin{array}{l}\text { Communication and Project } \\
\text { Design } \\
\text { eg. not being able to establish links } \\
\text { with the other local authority }\end{array}$ \\
\hline & $\begin{array}{l}\text { In-Service training } \\
\text { eg. high quality INSET which } \\
\text { facilitated relationship building and } \\
\text { familiarisation with materials }\end{array}$ & $\begin{array}{l}\text { In-Service training } \\
\text { eg. training taking place on INSET } \\
\text { days in schools created problems } \\
\text { for some staff }\end{array}$ \\
\hline & $\begin{array}{l}\text { Research team approach } \\
\text { eg. inclusive and collaborative } \\
\text { approach - staff felt involved }\end{array}$ & \\
\hline & $\begin{array}{l}\text { Enhancing current practice } \\
\text { eg. building upon established links } \\
\text { with the Primary schools }\end{array}$ & \\
\hline & $\begin{array}{l}\text { Other } \\
\text { eg. building an evidence base }\end{array}$ & \\
\hline
\end{tabular}




\begin{tabular}{|c|c|c|}
\hline \multirow[t]{5}{*}{ External to the Approach } & $\begin{array}{l}\text { Commitment, support and } \\
\text { expertise } \\
\text { eg. the commitment and support of } \\
\text { the Local Authority }\end{array}$ & $\begin{array}{l}\text { Systems, structures, priorities and } \\
\text { resources } \\
\text { eg. constraints of staffing making it } \\
\text { difficult for staff to cross sector to } \\
\text { team teach }\end{array}$ \\
\hline & $\begin{array}{l}\text { A whole school approach and } \\
\text { leadership } \\
\text { eg. the school prioritising the } \\
\text { project and affording time and } \\
\text { resources for it }\end{array}$ & $\begin{array}{l}\text { Leadership and communication } \\
\text { eg. difficulties in communication } \\
\text { with Pastoral Care staff }\end{array}$ \\
\hline & $\begin{array}{l}\text { School climate and ethos } \\
\text { eg. positive school climate }\end{array}$ & $\begin{array}{l}\text { Behaviour Support and } \\
\text { Inclusion/Exclusion } \\
\text { eg. negative connotations of } \\
\text { behaviour support in general }\end{array}$ \\
\hline & $\begin{array}{l}\text { Partnership working } \\
\text { eg. the full support of parents }\end{array}$ & $\begin{array}{l}\text { Partnerships (with parents) and } \\
\text { wider social influences } \\
\text { eg. lack of parental support }\end{array}$ \\
\hline & & $\begin{array}{l}\text { Pedagogy } \\
\text { eg. differing philosophical } \\
\text { positions with regard to working } \\
\text { with children held by primary and } \\
\text { secondary teachers, leading to } \\
\text { differences in approach in working } \\
\text { with children }\end{array}$ \\
\hline
\end{tabular}

Table 1: Analysis of themes to emerge from focus group discussions, classified according to affordances and constraints 


\section{Appendix 1: Templates around which focus group discussion was framed}

\section{Template 1}

What things would you consider have made a difference to pupil outcome? [Brainstorm followed by discussion]

\begin{tabular}{|l|l|l|}
\hline & \multicolumn{1}{|c|}{ Positive } & Negative \\
\hline About the Approach & & \\
\hline External to the & & \\
Approach & & \\
\hline
\end{tabular}

\section{Template 2}

In terms of how the project has been managed, what were the things which facilitated implementation and those which made it difficult? [Brainstorm followed by discussion]

\begin{tabular}{|l|l|l|}
\hline & Facilitated Implementation & Created Difficulties \\
\hline school/Local & & \\
Authority & & \\
\hline Related to the & & \\
Project Team & & \\
& & \\
\hline
\end{tabular}




\section{Appendix 2: Plenary Session}
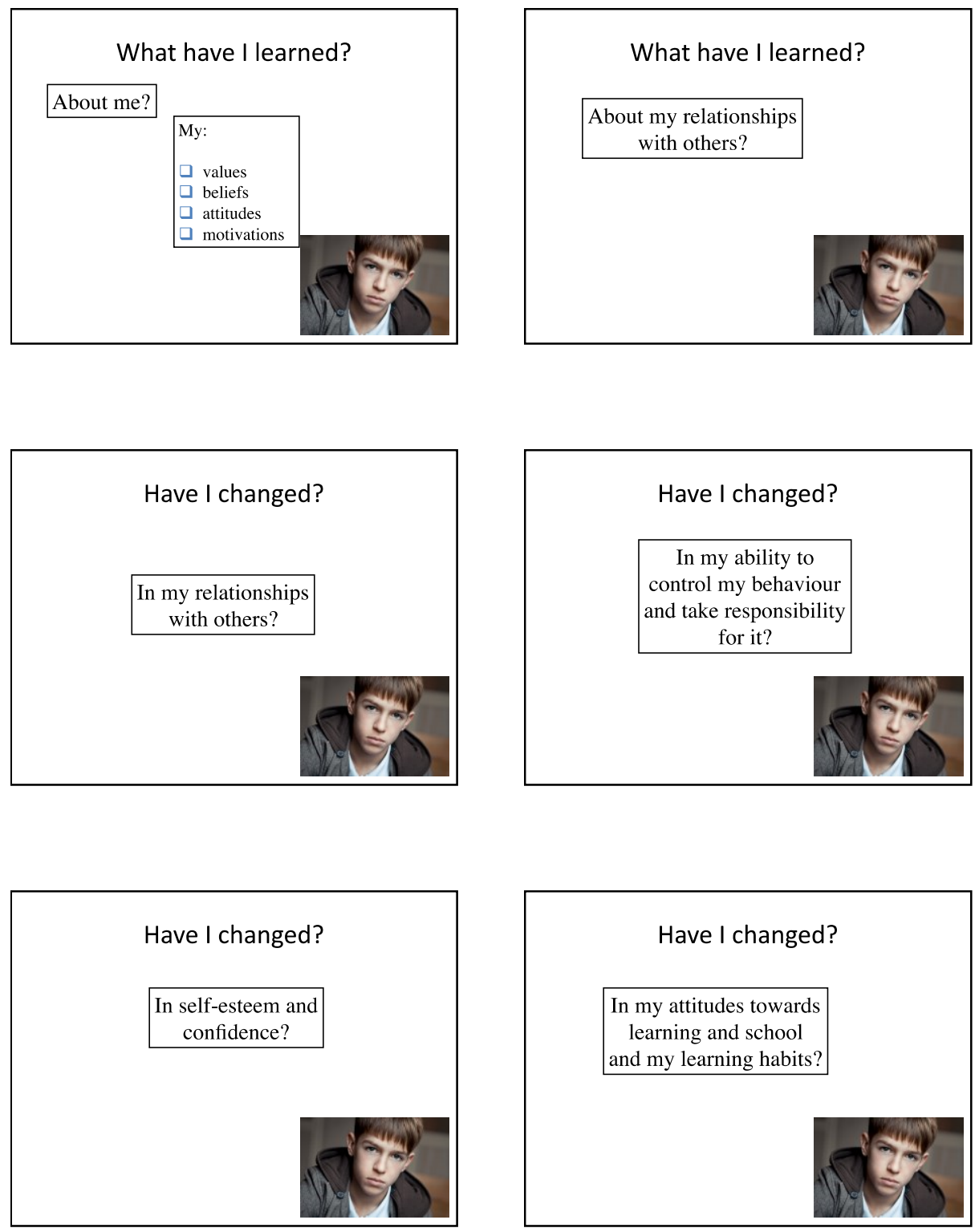


\section{Appendix 3: Journey to Excellence Responses [ $\mathrm{N}=26]$}

\section{Dimension 1}

\section{Engages young people in the highest quality learning activities}

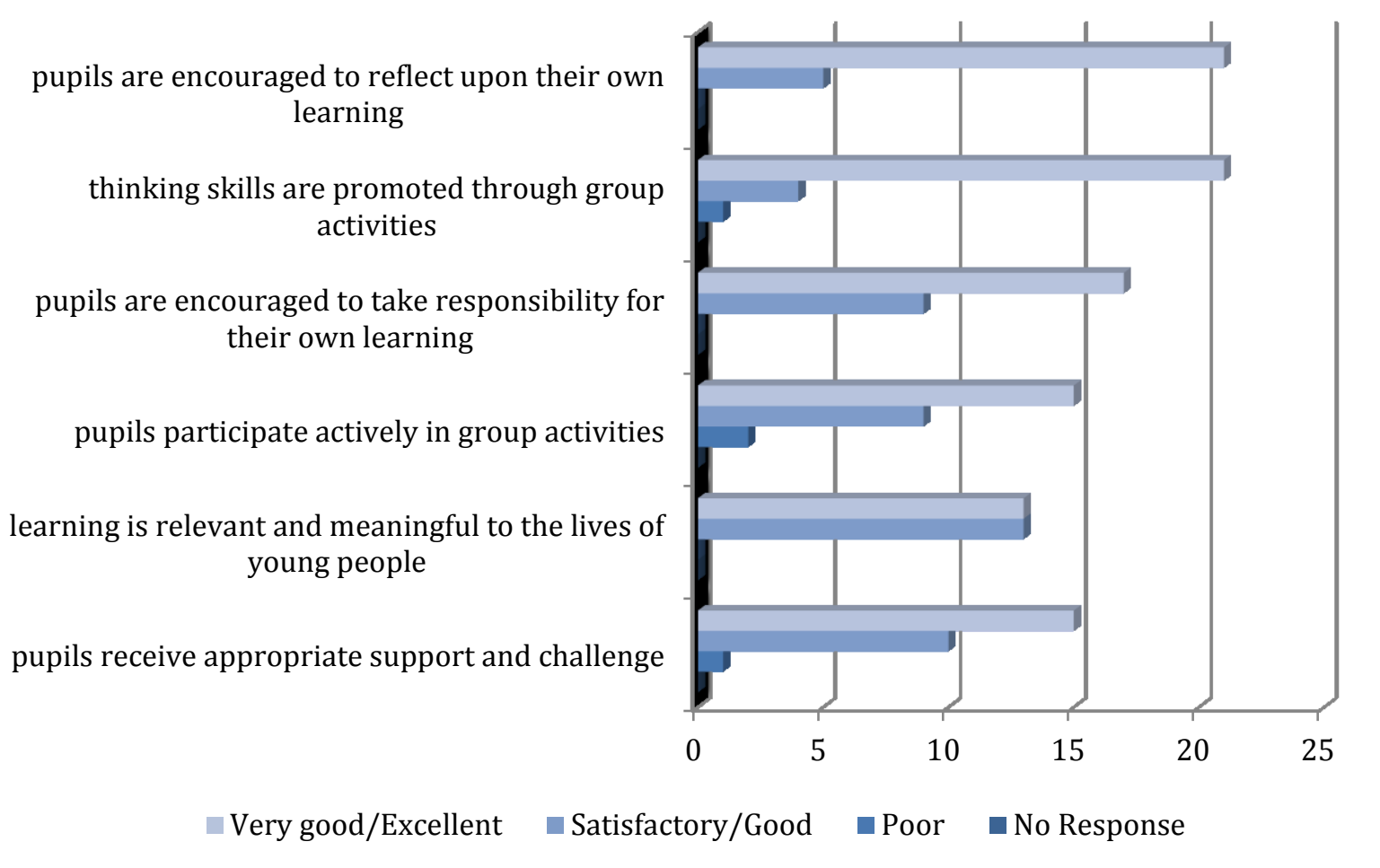




\section{Dimension 2}

\section{Focuses on outcomes and maximises success for all learners}

the desired pupil outcomes are appropriate to the needs of learners

the desired pupil outcomes are clearly articulated and shared with the learners

pupils receive ongoing feedback about their progress which feeds back into learning through the target-setting process

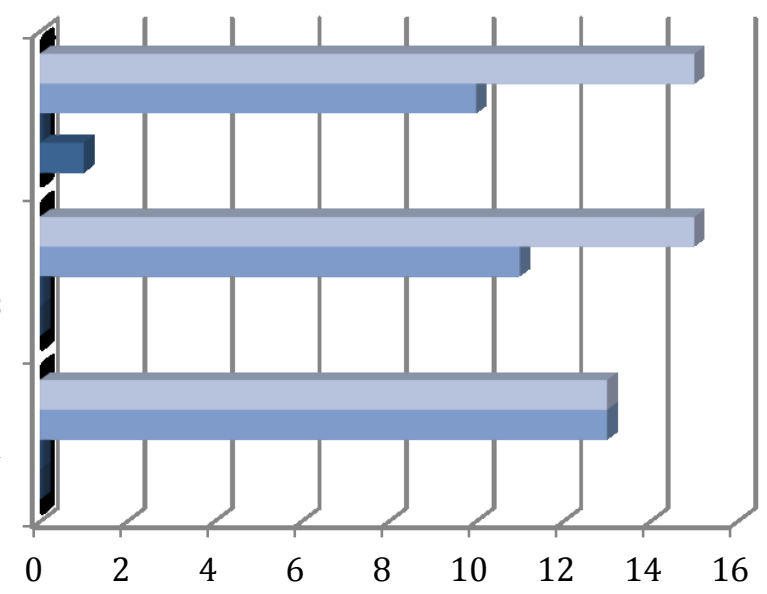

$\square$ Very good/Excellent $\square$ Satisfactory/Good $\square$ Poor $\square$ No Response

\section{Dimension 3}

\section{Develops a common vision across children and young people, parents and staff}

high quality INSET supports this process

inclusive practice is promoted through the initiative in which all children are valued and a sense of belonging is promoted

children, parents and staff work together to promote inclusive practice

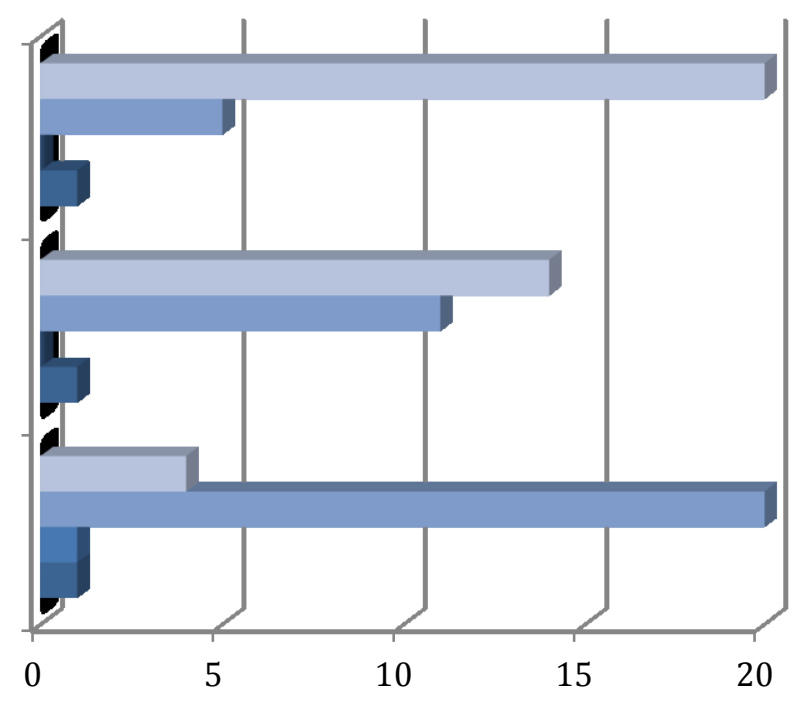

$\square$ Very good/Excellent $\square$ Satisfactory/Good $\square$ Poor $\square$ No Response 


\section{Dimension 4}

\section{Fosters high quality leadership at all levels}

the project is well led by the Research Team

communication systems [eg. newsletters, website] promote effective practice

the Cluster Leader provides high quality support and encouragement to Support Group Leaders

the Cluster Leader acts to facilitate the project within the Cluster

the project provides opportunities for SG Leaders to develop their leadership skills

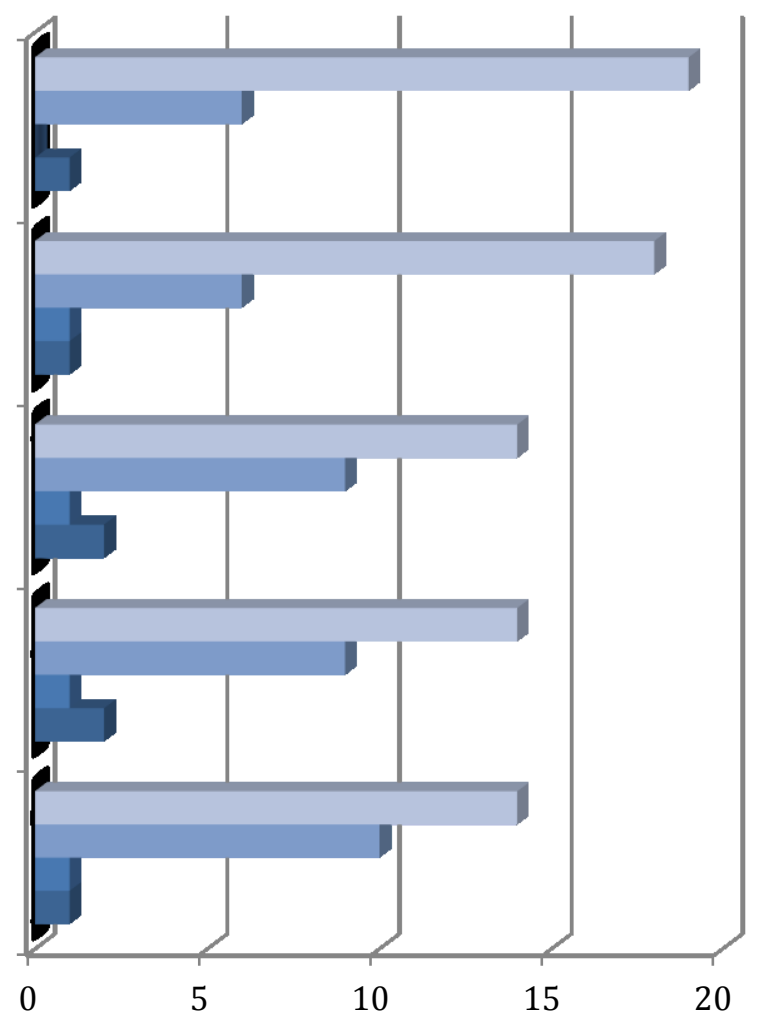

$\square$ Very good/Excellent $\square$ Satisfactory/Good $\square$ Poor $\square$ No Response 


\section{Dimension 5}

\section{Works in partnership with other agencies and its community}

the project fosters partnerships between local authorities

the project fosters partnerships between home and school

the project fosters partnerships between clusters

the project fosters partnerships within clusters

the project fosters partnerships between different agencies

the project fosters partnerships between academics and practitioners

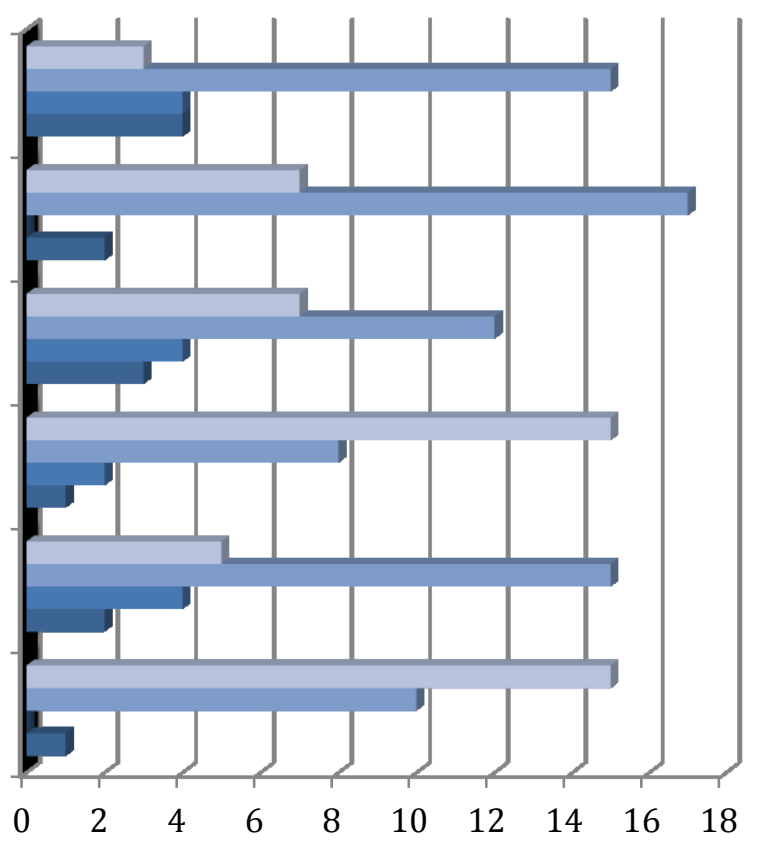

$\square$ Very good/Excellent $\square$ Satisfactory/Good $\square$ Poor $\square$ No Response 


\section{Dimension 6}

\section{Works together with parents to improve learning}

parents are given a detailed report of their child's progress at the end of intervention

parents are encouraged to discuss any concerns they have with the Sg Leader

advice is given to parents about how they can support their children

parents are kept regularly updated of their child's progress

parents are involved at all stages of the project

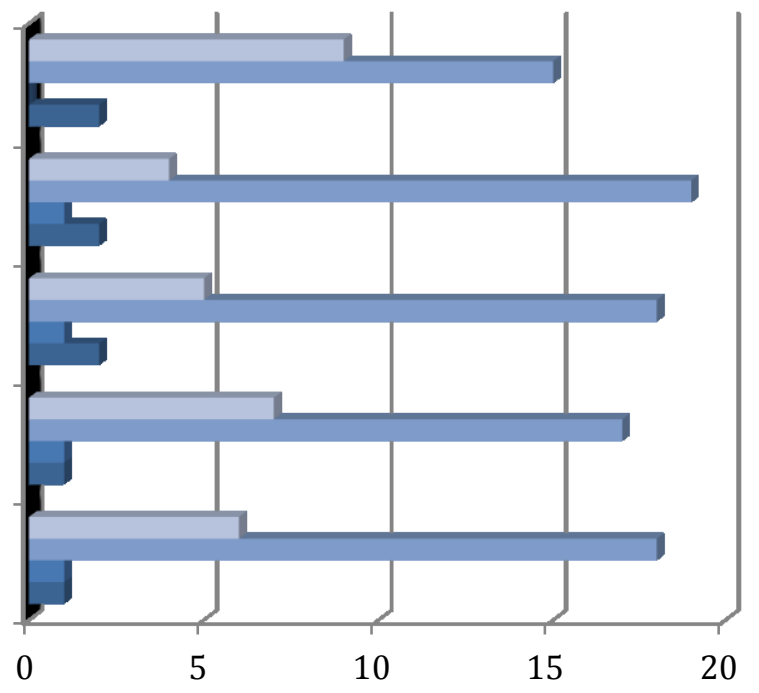

$\square$ Very good/Excellent $\square$ Satisfactory/Good $\square$ Poor $\square$ No Response

\section{Dimension 7}

\section{Reflects on its own work and thrives on challenge}

through the provision of a website, staff are enabled to share their practice

through Cluster arrangements ,Sg Leaders are encouraged to reflect upon and share their practice

through the provision of high quality INSET, staff are encouraged to share their practice

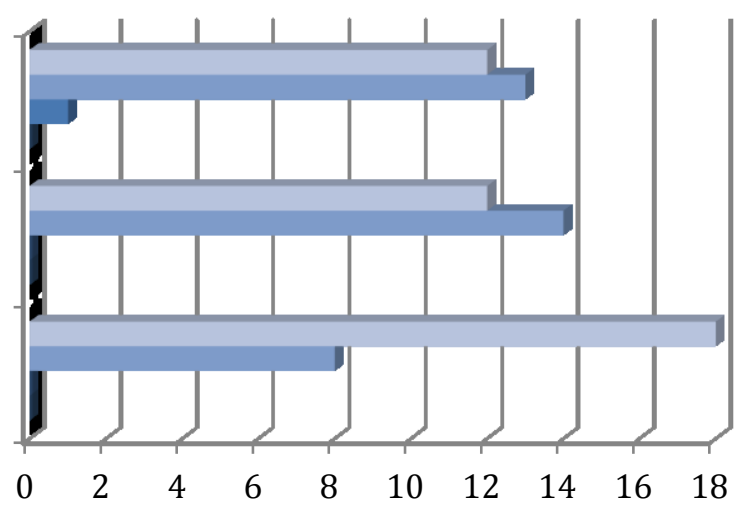

$\square$ Very good/Excellent $\square$ Satisfactory/Good $\square$ Poor $\square$ No Response 


\section{Dimension 8}

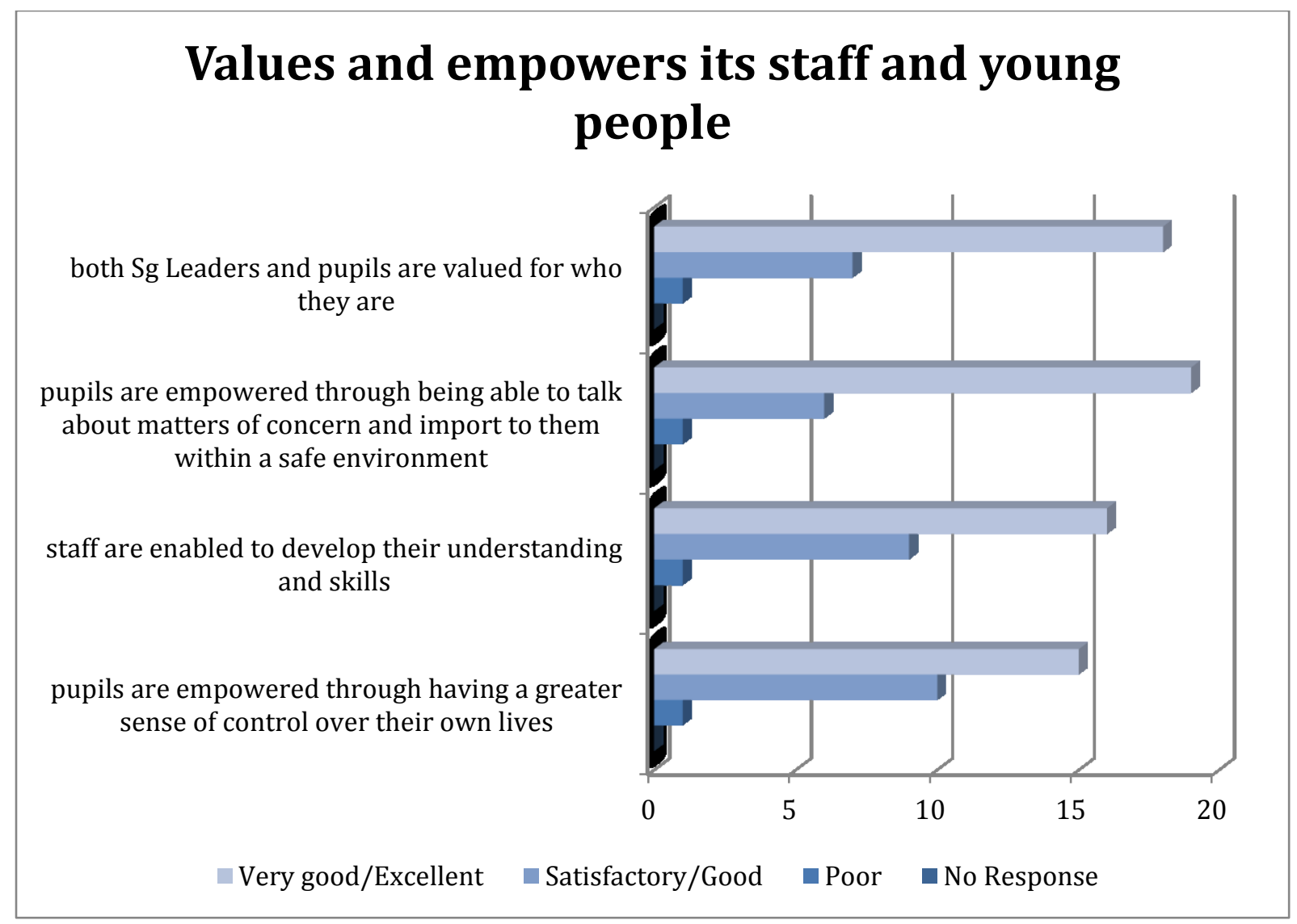




\section{Dimension 9}

\section{Promotes well-being and respect}

pupils are enabled to be affirmed and included

pupils are enabled to make changes which promote self-respect, self- esteem and selfefficacy

positive respectful relationships are promoted both within the group and within the wider school community

pupils are provided with appropriate support and challenge which enables them to gain insight into themselves and their relationships

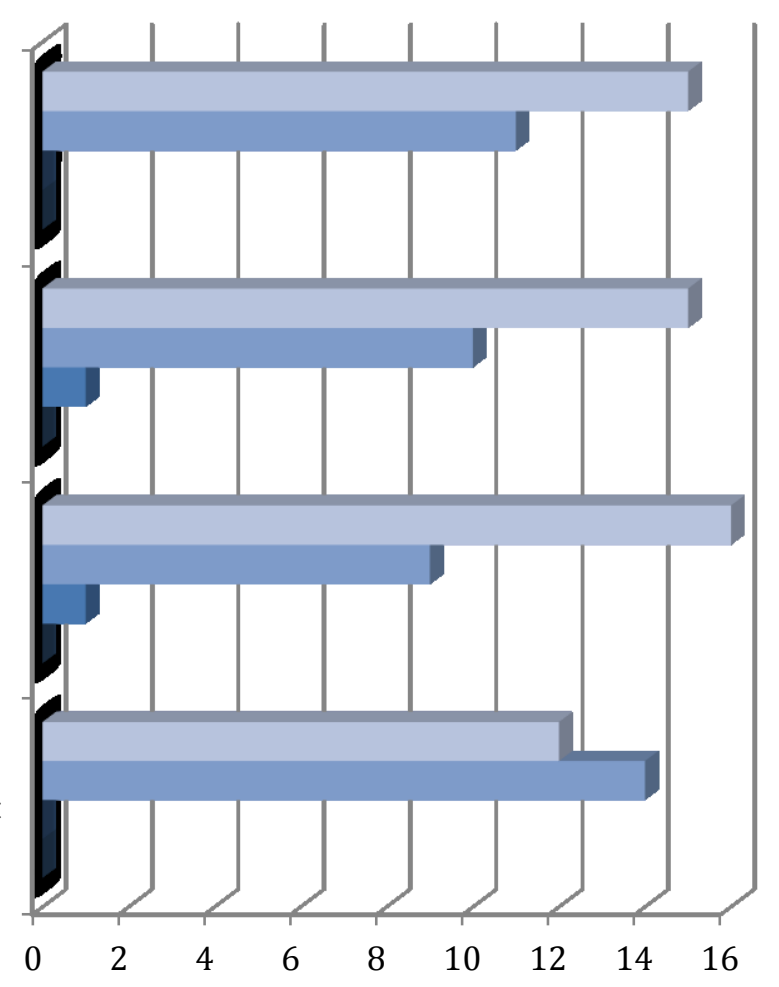

$\square$ Very good/Excellent $\square$ Satisfactory/Good $\quad$ Poor $\square$ No Response 


\section{Dimension 10}

\section{Develops a culture of ambition and achievement}

a sense of 'what can be' is fostered in pupils

staff are enabled to develop their full potential and to make a meaningful contribution to the life of the school

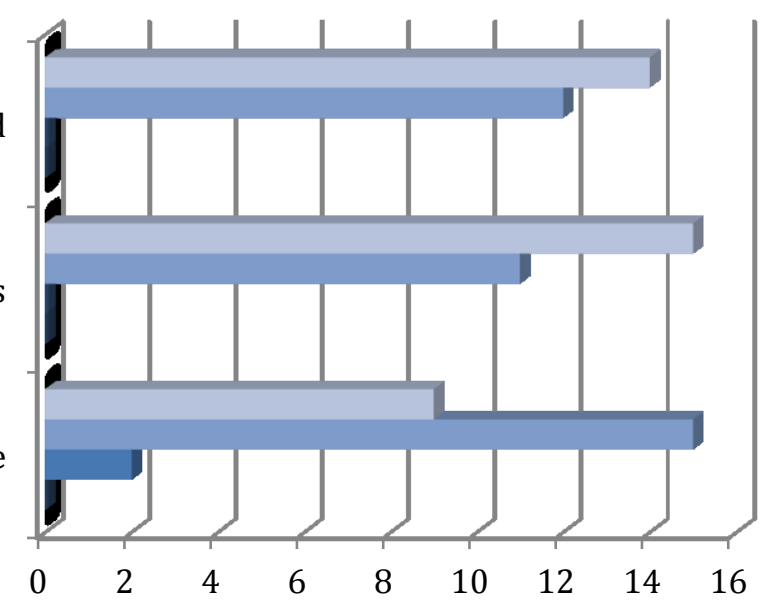

$\square$ Very good/Excellent $\square$ Satisfactory/Good $\square$ Poor $\square$ No Response 
